\title{
Neonatal Isolation Delays the Developmental Decline of Long- Term Depression in the CAI Region of Rat Hippocampus
}

\author{
Hsiao-Yun Ku', Yu-Fei Huang', Pei-Hsuan Chao', Chiung-Chun Huang' and Kuei-Sen Hsu*,1,2,3 \\ 'Department of Pharmacology, National Cheng Kung University, Tainan, Taiwan; ${ }^{2}$ Institute of Basic Medical Sciences, College of Medicine, \\ National Cheng Kung University, Tainan, Taiwan; ${ }^{3}$ Center for Gene Regulation and Signal Transduction Research, National Cheng Kung \\ University, Tainan, Taiwan
}

\begin{abstract}
Activity-dependent alterations of synaptic efficacy or connectivity are essential for the development, signal processing, and learning and memory functions of the nervous system. It was observed that, in particular in the CAI region of the hippocampus, low-frequency stimulation (LFS) became progressively less effective at inducing long-term depression (LTD) with advancing developmental age. The physiological factors regulating this developmental plasticity change, however, have not yet been elucidated. Here we examined the hypothesis that neonatal isolation (once per day for I $\mathrm{h}$ from postnatal days I-7) is able to alter processes underlying the developmental decline of LTD. We confirm that the magnitude of LTD induced by LFS (900 stimuli at I Hz) protocol correlates negatively with developmental age and illustrates that neonatal isolation delays this developmental decline via the activation of corticotrophin-releasing factor (CRF) system. Furthermore, this modulation appears to be mediated by an increased transcription of N-methyl-D-aspartate receptor NR2B subunits. We also demonstrate that intracerebroventricular injection of CRF postnatally mimicked the effect of neonatal isolation to increase the expression of NR2B subunits and delayed the developmental decline of LTD, which was specifically blocked by CRF receptor I antagonist NBI279 I 4 pretreatment. These results suggest a novel role for CRF in regulating developmental events in the hippocampus and indicate that although maternal deprivation is stressful for neonate, appropriate neonatal isolation can serve to promote an endocrine state that may regulate the gradual developmental change in the induction rules for synaptic plasticity in the hippocampal CAI region.

Neuropsychopharmacology (2008) 33, 2847-2859; doi:I0.1038/npp.2008.36; published online 26 March 2008
\end{abstract}

Keywords: neonatal isolation; long-term depression; N-methyl-D-aspartate receptor; NR2B subunit; corticotrophin-releasing factor; hippocampus

\section{INTRODUCTION}

Activity-induced long-lasting changes in synaptic efficacy are generally thought to be the cellular mechanism underlying the refinement of neuronal connections in developing nervous systems (Katz and Shatz, 1996; Zhang and Poo, 2001) and for the encoding of new information in the mature brain (Bliss and Collingridge, 1993; Martin et al, 2000). The persistence of such synaptic modifications can involve alterations in both the function of synaptic transmission and the structure of neuronal connections. Studies of synaptic plasticity have shown that repetitive electrical activity can rapidly induce persistent changes in the strength of synaptic transmission, known as long-term

*Correspondence: Professor Kuei-Sen Hsu, Department of Pharmacology, College of Medicine, National Cheng Kung University, No. I, University Road, Tainan 701, Taiwan,

Tel: + 886-6-2353535 ext. 5498,

Fax: + 886-6-2749296,

E-mail: richard@mail.ncku.edu.tw

Received 4 November 2007; revised 29 January 2008; accepted 13 February 2008 potentiation (LTP) and long-term depression (LTD) (Bliss and Lomo, 1973; Mulkey and Malenka, 1992). The molecular mechanisms of LTP and LTD have been extensively characterized (Malenka and Bear, 2004), especially in hippocampus, an area implicated in acquisition and storage of spatial memory in both rodents and humans (Squire, 1992; Burgess et al, 2002). The most striking feature of LTD is age-related decline. The standard low-frequency stimulation (LFS) protocol (900 stimuli at $1 \mathrm{~Hz}$ ), normally sufficient to induce LTD in the CA1 region of hippocampal slices from juvenile rats, is not effective in slices from adult rats (Dudek and Bear, 1992; Mulkey and Malenka, 1992). Although the processes underlying this developmental plasticity change remained to be established, it has been proposed that developmental alterations in $N$-methyl-Daspartate receptor (NMDAR) subunit composition and/or location at the synapses might have a role (Paupard et al, 1997; Dumas, 2005). However, the physiological factors regulating these developmental changes have not yet been elucidated.

Neonatal physiology and development are regulated by the ongoing mother-pup interactions. Maternal care during 
the first week of postnatal life has been shown to have profound and enduring impacts on hippocampal development and function (Liu et al, 2000; Bredy et al, 2003). We previously reported that neonatal isolation during the first postnatal week can accelerate the developmental switch in the molecular mechanisms underlying hippocampal CA1 LTP from a cyclic AMP-dependent protein kinase- to a $\mathrm{Ca}^{2+}$ /calmodulin-dependent protein kinase II-dependent pattern via the activation of corticotrophin-releasing factor (CRF) system (Huang et al, 2005). Thus far, no studies have investigated the effects of neonatal isolation on the induction of LTD. It became, therefore, of interest to study the possible role of an influence of maternal care on the agedependency nature of LTD induction. To investigate this issue, we utilize a mild maternal separation paradigm (once per day for $1 \mathrm{~h}$ from postnatal days 1-7, P1-7) followed by examining the LFS-induced LTD (LFS-LTD) at different postnatal ages. Our results indicate that this neonatal isolation paradigm delays the developmental decline of LTD via the activation of CRF system, and that the developmental patterns of NR2B subunits are highly correlated with the levels of LTD induction.

\section{MATERIALS AND METHODS}

\section{Animals and Neonatal Isolation Paradigm}

All procedures were performed according to NIH guidelines for animal research and approved by the Institutional Animal Care and Use Committee at National Cheng Kung University. Rat pups were isolated from the dam, nest, and siblings for a period of $1 \mathrm{~h}$ (between 1000 and $1100 \mathrm{~h}$ ) once per day over P1-7 as described previously (Huang et al, 2005). Animals of both isolated and non-isolated groups received equal amounts of handling. Pups of the isolation treatment group were placed in individual plastic cups ( $9 \mathrm{~cm}$ diameter) in an environmentally controlled chamber maintained at nest temperature $34^{\circ} \mathrm{C}$. At the end of the isolation period, pups were returned to the nest with the dam. All efforts were made to minimize animal suffering and to use only the number of animals necessary to produce reliable scientific data.

\section{Electrophysiological Studies in Hippocampal Slices}

Hippocampal slices were prepared from 2- to 8-week-old Sprague-Dawley rats after decapitation under halothane anesthesia, allowed to recover for a minimum of $1 \mathrm{~h}$ at room temperature $24-26^{\circ} \mathrm{C}$, and then transferred to a submersion-type recording chamber continually perfused with $30-$ $32^{\circ} \mathrm{C}$ oxygenated $\left(95 \% \mathrm{O}_{2}-5 \% \mathrm{CO}_{2}\right)$ artificial cerebrospinal fluid (aCSF) solution containing $117 \mathrm{mM} \mathrm{NaCl}, 4.7 \mathrm{mM} \mathrm{KCl}$, $2.5 \mathrm{mM} \mathrm{CaCl}_{2}, 1.2 \mathrm{mM} \mathrm{MgCl}, 25 \mathrm{mM} \mathrm{NaHCO}, 1.2 \mathrm{mM}$ $\mathrm{NaH}_{2} \mathrm{PO}_{4}$ and glucose, 11. Extracellular and whole-cell patch-clamp recordings were carried out with Axoclamp-2B or Axopatch 200B amplifier (Axon Instruments, Foster City, $\mathrm{CA}$ ). The responses were low-pass filtered at $2 \mathrm{kHz}$, digitally sampled at 5-10 kHz, and analyzed using pCLAMP software (Version 8.0; Axon Instruments). The evoked postsynaptic responses were induced in CA1 stratum radiatum by stimulation ( $0.02 \mathrm{~ms}$ duration) of Schaffer collateral/commissural afferents at $0.033 \mathrm{~Hz}$ with a bipolar stainless steel stimulating electrode. Field excitatory postsynaptic potentials (fEPSPs) were recorded with a glass pipette filled with $1 \mathrm{M} \mathrm{NaCl}$ (2-3 M $\Omega$ resistance) and the initial slope was measured. The strength of synaptic transmission was quantified by measuring the slope of fEPSP. LTD was induced using a standard protocol of 900 stimuli at $1 \mathrm{~Hz}$. Whole-cell recording of excitatory postsynaptic currents (EPSCs) was made from CA1 pyramidal cells, which were identified under a DIC microscope. Patch pipettes (3-5 M $\Omega$ ) filled with the following internal solution were used (in $\mathrm{mM}): 130 \mathrm{CsMeSO}_{3}, 8 \mathrm{NaCl}, 10$ HEPES, 0.5 EGTA, 4 $\mathrm{Na}_{2}$ ATP, $0.3 \mathrm{Na}_{3} \mathrm{GTP}, 5$ QX-314 N-(2,6-dimethyl-phenylcarbamoylmethyl) triethylammonium bromide, which had an osmolarity of 290-295 mOsm and pH of 7.2. The amplitude of evoked EPSCs was measured. To ensure stability of the whole-cell recordings, electrical stimulation was initiated before the cell was patched. We waited for approximately $5 \mathrm{~min}$ in the cell-attached configuration before break-in to wash off any residual internal solution spilled from the approaching pipette. For recording NMDAR-mediated EPSCs, cells were clamped at $-60 \mathrm{mV}$ in $\mathrm{Mg}^{2+}$-free aCSF. Series and input resistances were monitored throughout each experiment. If the value of series resistance changed more than $15 \%$ over the course of the experiment, data were discarded. Data for current-voltage relationship were obtained by varying the postsynaptic holding potential between -100 and $60 \mathrm{mV}$ in step of $20 \mathrm{mV}$. The decay time constant of NMDAR-mediated EPSCs was calculated by fitting the decay of the synaptic current with double exponential equations of the expression $I(t)=I_{\mathrm{f}} * \exp \left(-t / \tau_{f}\right)$ $+I_{s} * \exp \left(-t / \tau_{s}\right)$, where $I_{\mathrm{f}}$ and $I_{s}$ are the amplitudes of the fast- and slow-decay components, $\tau_{\mathrm{f}}$ and $\tau_{\mathrm{s}}$ and are their respective decay time constants used to fit the data. To conveniently compare decay time, we used a weighted mean decay time constant $\left(\tau_{\mathrm{w}}\right)$, which was calculated using the expression $\tau_{\mathrm{w}}=\left[I_{\mathrm{f}} /\left(I_{\mathrm{f}}+I_{\mathrm{s}}\right)\right] * t_{\mathrm{f}}+\left[I_{\mathrm{s}} /\left(I_{\mathrm{f}}+I_{\mathrm{s}}\right)\right] * t_{\mathrm{s}}$ described by Rumbaugh and Vicini (1999).

\section{Western Blotting}

The microdissected tissue samples were transferred into icecold lysis buffer ( $\mathrm{pH}$ 7.4) containing a cocktail of protein phosphatase and proteinase inhibitors $(50 \mathrm{mM}$ Tris- $\mathrm{HCl}$, $100 \mathrm{mM} \mathrm{NaCl}, 15 \mathrm{mM}$ sodium pyrophosphate, $50 \mathrm{mM}$ sodium fluoride, $1 \mathrm{mM}$ sodium orthovanadate, $5 \mathrm{mM}$ EGTA, $5 \mathrm{mM}$ EDTA, $1 \mathrm{mM}$ phenylmethylsulfonyl fluoride, $1 \mu \mathrm{M}$ microcystin-LR, $1 \mu \mathrm{M}$ okadaic acid, $0.5 \%$ Triton $\mathrm{X}-100$, $2 \mathrm{mM}$ benzamidine, $60 \mu \mathrm{g} / \mathrm{ml}$ aprotinin, and $60 \mu \mathrm{g} / \mathrm{ml}$ leupeptin) to avoid dephosphorylation and degradation of proteins, and ground with a pellet pestle (Kontes glassware, Vineland, NJ). Samples were sonicated and spun down at $15000 \mathrm{~g}$ at $4^{\circ} \mathrm{C}$ for $10 \mathrm{~min}$. The supernatant was then assayed for total protein concentration using Bio-Rad Bradford Protein Assay Kit (Hercules, CA). Each sample was separated in 7\% SDS-PAGE gel. Following the transfer on nitrocellulose membranes, blots were blocked in TBS containing $3 \%$ bovine serum albumin and $0.01 \%$ Tween 20 for $1 \mathrm{~h}$ and then blotted for $2 \mathrm{~h}$ at room temperature with antibody that recognizes NR1 (1:1000; Chemicon, Temecula, CA), NR2A (1:500; Santa Cruz Biotechnology, Santa Cruz, CA), NR2B (1:200; Santa Cruz Biotechnology) or $\beta$-actin (1 : 20000 ; Sigma-Aldrich, St Louis, MO). It was then 
probed with HRP-conjugated secondary antibody for $1 \mathrm{~h}$ and developed using the ECL immunoblotting detection system (Amersham Pharmacia Biotech, Piscatway, NJ, USA). Immunoblots were analyzed by densitometry using Bio-profil BioLight PC software. Only film exposures that were in the linear range of the ECL reaction were used for quantification analysis. Expression of NR1, NR2A, and NR2B was evaluated relative to that for $\beta$-actin. Background correction values were subtracted from each lane to minimize the variability across membranes.

\section{Quantitative Real-Time RT-PCR}

Total RNA was isolated from frozen hippocampal CA1 tissues using TriReagent kit (Molecular Research Center, Cincinnati, OH), treated with RNase-free DNase (RQ1; Promega) to remove the potential contamination of genomic DNA. Approximately $1 \mathrm{ng}$ of RNA was reverse transcribed and amplified following the quantitative onestep real-time RT-PCR technique (Titanium One-Step RTPCR kit; BD Biosciences Clontech, Palo Alto, CA), with both RT and PCR in the same tube. Real-time RT-PCR was performed on the Roche LightCycler instrument (Roche Diagnostics, Indianapolis, IN) using the FastStart DNA Master SYBR Green I kit (Roche Applied Science) as described by the manufacturer. The PCR mixtures were incubated at $95^{\circ} \mathrm{C}$ for $10 \mathrm{~min}$, and then 35 PCR cycles were conducted $\left(95^{\circ} \mathrm{C}\right.$ for $10 \mathrm{~s}, 55^{\circ} \mathrm{C}$ for $15 \mathrm{~s}$, and $68^{\circ} \mathrm{C}$ for $20 \mathrm{~s}$ ). The primer combinations were designed by referring to the rat study by Pickering et al (2006): NR1, 5'-CTGCAACCCTC ACTTTTGAG-3' (forward) and 5'-TGCAAAAGCCAGCTGC ATCT-3' (reverse); NR2A, 5'-GACGGTCTTGGGATCTTAA C-3' (forward) and $5^{\prime}$-TGACCATGAAATTGGTGCAGG-3' (reverse); NR2B, 5'-TGCACAATTACTCCTCGACG-3' (forward) and $5^{\prime}$-TCCGATTCTTCTTCTGAGCC- $3^{\prime}$ (reverse); $\beta$-actin, $5^{\prime}$-TTCTACAATGAGCTGCGTGTGGC-3' (forward) and $5^{\prime}$-CTCATAGCTCTTCTCCAGGGAGGA-3' (reverse). Real-time RT-PCRs on mRNA obtained from control or neonatal isolated rat hippocampal CA1 total RNA samples were performed at the same time. PCR amplifications were repeated in duplicate. A melting curve was created at the end of the PCR cycle to confirm that a single product was amplified. Data were analyzed by the LightCycler quantification software to determine the threshold cycle above the background for each reaction. The relative transcript amount of the gene of interest, which was calculated using standard curves of serial RNA dilutions, was normalized to that of $\beta$-actin of the same RNA, because it lacks significant expression changes after neonatal isolation (Huang et al, 2005).

\section{Drug Treatment}

To determine whether intracerebroventricular (i.c.v.) injection of CRF mimics neonatal isolation in neonatal brain, pups received i.c.v. injection of a $1 \mu \mathrm{l}$ solution containing either vehicle (aCSF) or CRF $(0.05 \mu \mathrm{M}$ in vehicle) into right hemisphere with a 30 -gauge needle connected to a $5 \mu \mathrm{l}$ Hamilton syringe. The location of injection was $2 \mathrm{~mm}$ rostral, $1.5 \mathrm{~mm}$ lateral to bregma, and $2 \mathrm{~mm}$ deep to the skull surface as described previously (Han and Holtzman, 2000; Huang et al, 2005). CRF was injected every second day from P3 to P7. In some experiments, a selective CRF receptor 2 (CRF-R2) antagonist, K41498 (2 nmol in vehicle), was dissolved in aCSF and i.c.v. administered $5 \mathrm{~min}$ before CRF injection. The dose of K41498 was selected on the basis of a previous study (Lawrence et al, 2002). Recombinant human/rat CRF, 5-chloro- $N$-(cyclopropylmethyl)-2-methyl$N$-propyl- $N$-(2,4,6-trichlorophenyl)-4,6-pyrimidinediamine (NBI27914), K41498, (D)-2-amino-5-phosphonopentanoic acid (D-APV), DL-threo- $\beta$-benzyloxyaspartate (DL-TBOA), ( + )-MK-801, [( \pm )- $\left.\left(R^{\star}, S^{\star}\right)\right]-\alpha$-(4-hydroxyphenyl)- $\beta$-methyl4-(phenylmethyl)-1-piperidine propanol (Ro 25-6981), and ifenprodil were obtained from Tocris Cookson (Bristol, UK). (R)-[(S)-1-(4-bromo-phenyl)-ethylamino]-(2,3-dioxo1,2,3,4-tetrahydroquinoxalin-5-yl)-methyl]-phosphonic acid (NVP-AAM077) was a generous gift from Novartis Pharma (AG, Switzerland).

\section{Data Analysis}

All data are expressed as means \pm SEM, and unless stated otherwise, the statistic significance was determined using a one-way analysis of variance (ANOVA) for repeated measurements with a post hoc Tukey-Kramer test or Student's $t$-test. Probability values of $p<0.05$ were considered to represent significant differences.

\section{RESULTS}

\section{Developmental Downregulation of LFS-LTD}

We first examined whether the magnitude of LFS-LTD was developmentally regulated. The amount of LTD of fEPSPs induced by LFS was compared over a range of different developmental ages in rats (P13-57). In agreement with previous reports (Dudek and Bear, 1992; Mulkey and Malenka, 1992), LFS induced a robust and stable LTD of fEPSPs in slices from young rats at P13-22 (Figure 1a and c), but became progressively less effective at inducing LTD with advancing developmental age. Recordings made from P27-57 rats showed little or no LTD after LFS (Figure 1b and c). Our results established an age-related loss of LTD induced by LFS in the CA1 region of rat hippocampus (Figure 1c; $p<0.001, \mathrm{~F}_{(5,49)}=12.68$ ). There was a clear inverse correlation between the age and the amount of LFSLTD $(r=0.76 ; p<0.001)$ (Figure 7a).

\section{Neonatal Isolation Delays the Developmental Decline of LFS-LTD}

Considering the importance of maternal care during the first week of postnatal life for the hippocampal development and function (Liu et al, 2000; Bredy et al, 2003), we examined the influence of neonatal isolation on agedependency profile of LFS-LTD. The magnitude of LTD was not significantly affected by neonatal isolation in slices from young rats at P13-22 (Figure $1 \mathrm{a}$ and $\mathrm{c}$ ). In contrast to the slice from control rats, the slices from neonatal isolated rats at P27-43 exhibited a robust LFS-LTD (Figure $1 \mathrm{~b}$ and c). However, slices from both control and neonatal isolated rats at P55-57 failed to express a significant LFS-LTD (Figure 1c). 
a

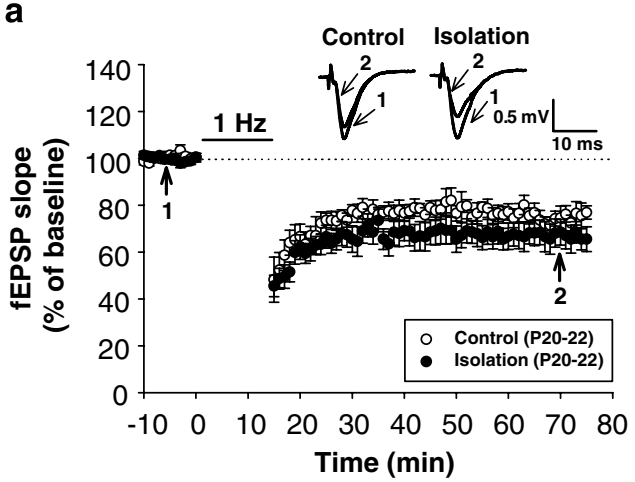

b

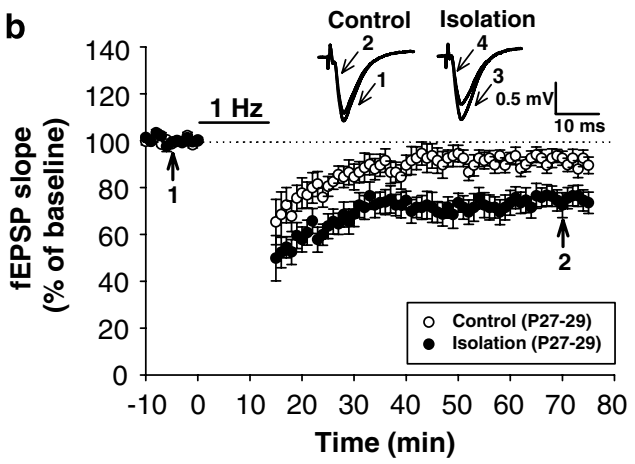

C

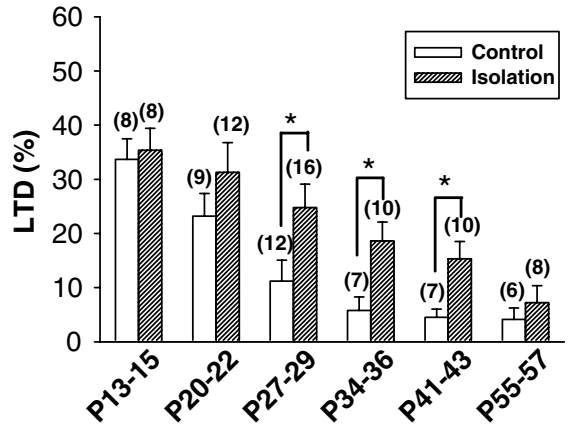

d

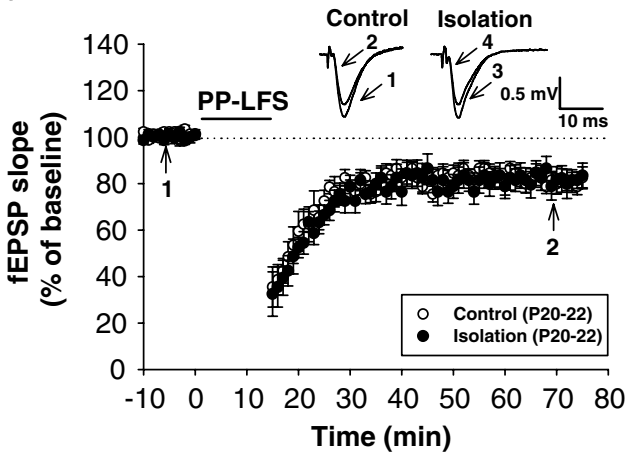

e

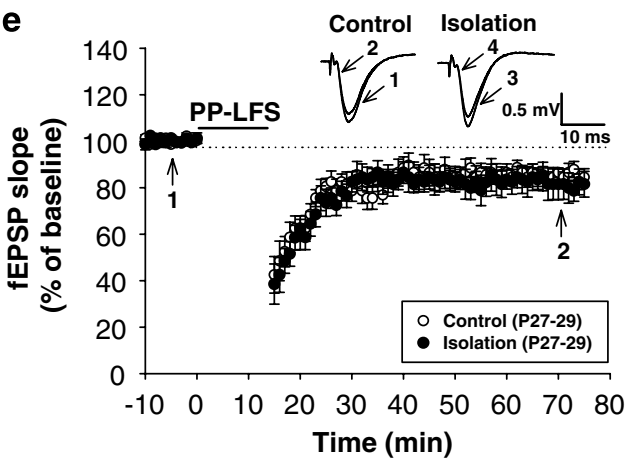

$\mathbf{f}$

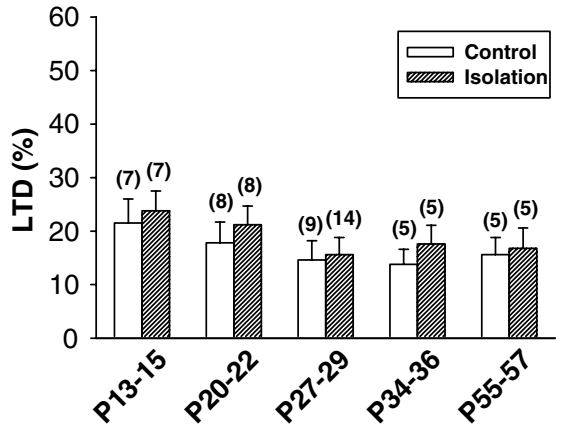

Figure I LTD induction in the hippocampal CAI region. (a and b) Effects of neonatal isolation on the induction of LTD by LFS ( I Hz for I5 min) in (a) postnatal day (P)20-22 and (b) P27-29 slices. (c) Summary of effects of neonatal isolation on LTD as function of postnatal ages. (d and e) Effects of neonatal isolation on the LTD induced by paired-pulse low-frequency stimulation (PP-LFS; 50-ms interstimulus interval) at I Hz for I 5 min in the presence of D-APV $(50 \mu \mathrm{M})$ in (d) P20-22 and (e) P27-29 slices. (f) Summary of effects of neonatal isolation on PP-LFS-induced LTD as function of postnatal age. The superimposed fEPSPs in the inset illustrate respective recordings from example experiments taken at the time indicated by number. Dash lines show level of baseline. The numbers in parentheses indicate the number of slices examined (4-I0 rats for each group). $* 0<0.05$ as compared with the control group at the same postnatal age.

Homosynaptic LTD can be induced in the hippocampal CA1 region by several stimulus protocols. Kemp and Bashir (1997) found that paired-pulse LFS (PP-LFS; 900 stimuli at $1 \mathrm{~Hz}$ with a $50-\mathrm{ms}$ interstimulus interval) can induce LTD (PP-LFS-LTD) in the CA1 region of the adult hippocampus and that this LTD is dependent on the metabotropic glutamate receptor activation. We therefore tested whether neonatal isolation also alters the induction of PP-LFS-LTD. As shown in Figure 1d-f, in the presence of NMDA receptor antagonist D-APV $(50 \mu \mathrm{M})$, PP-LFS reliably induced LTD in slices from rats at P13-57. In marked contrast to LFS-LTD, there was no significant age-related loss of LTD induced by PP-LFS $\left(p=0.23 ; \mathrm{F}_{(2,34)}=2.34\right)$. Moreover, the amount of PP-LFS-LTD was not significantly affected by neonatal isolation at all postnatal age examined (Figure 1f).

\section{LTD Observed in Slices from Neonatal Isolated Rats Relies on the Activation of NR2B-Containing NMDARs}

Because the activation of NMDARs is required for LFS-LTD in the hippocampal CA1 region (Dudek and Bear, 1992), it was then examined whether LTD observed in slices from neonatal isolated rats at P27-29 is also NMDAR-dependent. We found that blockade of NMDARs by pretreatment with D-APV $(50 \mu \mathrm{M}, n=6$ slices from five rats) completely prevented the induction of LTD by LFS (Figure 2b), confirming that the induction of LTD in slices from neonatal isolated rats was fully NMDAR-dependent. NMDARs are heteromeric complexes containing at least one NR1 subunit and two or three NR2 subunits (Seeburg, 1993). Given that the presence of different NR2 subunits 

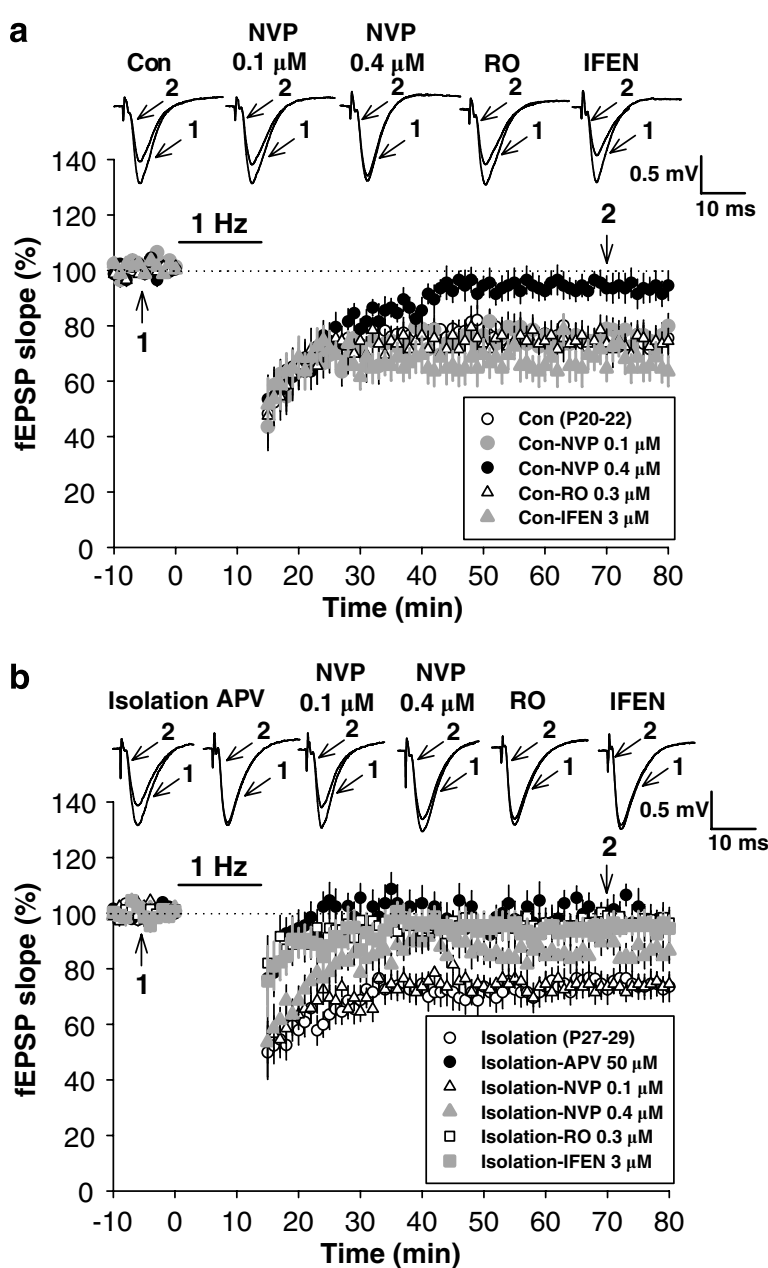

Figure 2 Neonatal isolation facilitates LTD induction in hippocampal CAI region by NR2B-containing NMDAR activation. (a) LFS-induced LTD in slices from control rats at P20-22 was suppressed by NVP-AAM077 (NVP, $0.4 \mu \mathrm{M}$ ), but not by NVP-AAM077 (NVP, $0.1 \mu \mathrm{M}$ ), Ro 25-698I (RO, $0.3 \mu \mathrm{M}$ ), or ifenprodil (IFEN, $3 \mu \mathrm{M}$ ). (b) LFS-induced LTD in slices from neonatal isolated rats at P27-29 was suppressed by APV $(25 \mu \mathrm{M})$, NVPAAM077 (NVP, $0.4 \mu \mathrm{M}$ ), Ro 25-698I (RO, $0.3 \mu \mathrm{M}$ ), and ifenprodil (IFEN, $3 \mu \mathrm{M})$, but not by NVP-AAM077 $(0.1 \mu \mathrm{M})$. The superimposed fEPSPs in the inset illustrate respective recordings from example experiments taken at the time indicated by number. Dash lines show level of baseline.

may confer distinct gating and pharmacological properties to heteromeric NMDARs (Monyer et al, 1994) and couple them to different cytoplasmic signaling cascades (Sala et al, 2000), we also discerned which NMDAR sub-populations are required for the induction of LFS-LTD in slices from neonatal isolated rats. In control experiments, the NR2Aselective antagonist NVP-AAM077 (IC50 of $14 \mathrm{nM}$ and $1.8 \mu \mathrm{M}$ for NR1/NR2A and NR1/NR2B, respectively) (Auberson et al, 2002) produced a concentration-dependent inhibition of LFS-LTD in slices from control rats at P20-22. At the NR2A-selective concentration of $0.1 \mu \mathrm{M}$, NVPAAM077 had no effect on LFS-LTD ( $n=5$ slices from four rats; $p>0.05)$. However, NVP-AAM077 at $0.4 \mu \mathrm{M}$, a concentration that inhibits both NR2A- and NR2B-containing NMDARs (Bartlett et al, 2007), produced a significant inhibition of LFS-LTD ( $n=6$ slices from four rats; $p<0.05$ ) (Figure 2a). To test the role of NR2B-containing NMDARs in the induction of LFS-LTD, two NR2B-selective antagonists, Ro 25-6981 (IC50 of $9 \mathrm{nM}$ and $52 \mu \mathrm{M}$ for NR1/NR2B and NR1/NR2A, respectively) (Fischer et al, 1997) and ifenprodil (IC50 of 0.34 and $136 \mu \mathrm{M}$ for NR1/NR2B and NR1/NR2A, respectively) (Williams, 1993), were used. As shown in Figure 2a, application of neither Ro 25-6981 $(0.3 \mu \mathrm{M}, n=5$ slices from four rats) nor ifenprodil $(3 \mu \mathrm{M}$, $n=5$ slices from four rats) significantly affected the induction of LFS-LTD. In slices from neonatal isolated rats at P27-29, NVP-AAM077 $(0.1 \mu \mathrm{M})$ did not affect LFS-LTD $(n=5$ slices from five rats; $p>0.05)$ whereas a concentration of $0.4 \mu \mathrm{M}$ produced a significant inhibition of LFS-LTD $(n=6$ slices from five rats; $p<0.05)$ (Figure $2 b)$. Surprisingly, in contrast to the failure of Ro 25-6981 or ifenprodil to block LTD in slices from control rats at P20-22, in the presence Ro 25-6981 (0.3 $\mu \mathrm{M}, n=6$ slices from five rats) or ifenprodil ( $3 \mu \mathrm{M}, n=6$ slices from five rats), LFS failed to induce LTD in slices from neonatal isolated rats at P27-29 (Figure 2b). These results suggest that the induction of LFSLTD in slices from neonatal isolated rats at P27-29 relies on the activation of NR2B-containing NMDARs.

Having confirmed that the activation of NR2B-containing NMDARs is obligatory for the induction of LFS-LTD in slices from neonatal isolated rats, we next examined whether neonatal isolation may lead to an upregulation of NMDAR function in the hippocampal CA1 neurons. We used whole-cell patch-clamp recording to compare the extent of NMDAR-mediated EPSCs in hippocampal CA1 pyramidal neurons in slices from control and neonatal isolated rats at P27-29. NMDAR-mediated component of

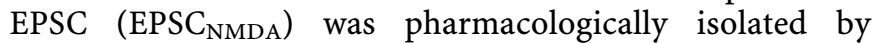
adding CNQX $(10 \mu \mathrm{M})$, a non-NMDAR antagonist, and bicuculline methiodide $(20 \mu \mathrm{M})$, a $\mathrm{GABA}_{\mathrm{A}}$ receptor antagonist. This current was completely blocked by D-APV $(50 \mu \mathrm{M})$, indicating that it was mediated by NMDARs. Although the neurons from neonatal isolated rats exhibited slightly larger $\mathrm{EPSC}_{\mathrm{NMDA}}$ than that in slices from control rats, it did not reach statistical significance. The $10-90 \%$ rise time of the $\mathrm{EPSC}_{\mathrm{NMDA}}$ was $6.3 \pm 0.4 \mathrm{~ms}(n=8$ slices from six rats) in neurons from neonatal isolated rats, which was not significantly different from that in neurons from control rats $(5.8 \pm 0.3 \mathrm{~ms}, n=8$ slices from six rats). However, the decay of EPSC $\mathrm{NMDA}_{\mathrm{N}}$ was slower $(p<0.01)$ in neurons from neonatal isolated rats (a mean weighted time constant, $164 \pm 12 \mathrm{~ms}, n=8$ slices from six rats) than that in neuron from control rats $(92 \pm 11 \mathrm{~ms}, n=8$ slices from six rats) (Figure 3f). However, current-voltage relationship of peak EPSC $_{\text {NMDA }}$ in neurons from neonatal isolated $(n=5$ slices from five rats) and control rats $(n=5$ slices from five rats) was almost superimposable (Figure 3a).

It is possible that the slower decay kinetics of $\mathrm{EPSC}_{\mathrm{NMDA}}$ is attributable to an increase in function of NR2B-containing NMDARs after neonatal isolation (Tovar and Westbrook, 1999). To test this idea, we used pharmacological antagonists for NR2A and NR2B to measure the synaptically induced NR2A- and NR2B-mediated EPSC $_{\mathrm{NMDA}}$ in CA1 pyramidal neurons from neonatal isolated and control rats at P27-29. Application of 0.1 and $0.4 \mu \mathrm{M}$ NVP-AAM077 suppressed $\mathrm{EPSC}_{\mathrm{NMDA}}$ by $52.7 \pm 4.2 \%$ ( $n=6$ slices from five rats) and $75.6 \pm 4.5 \%$ ( $n=6$ slices from five rats), respectively, in neurons from control rats. We found that the inhibitory effect of $0.4 \mu \mathrm{M}$ NVP-AAM077 $(60.4 \pm 4.3 \%, n=6$ 

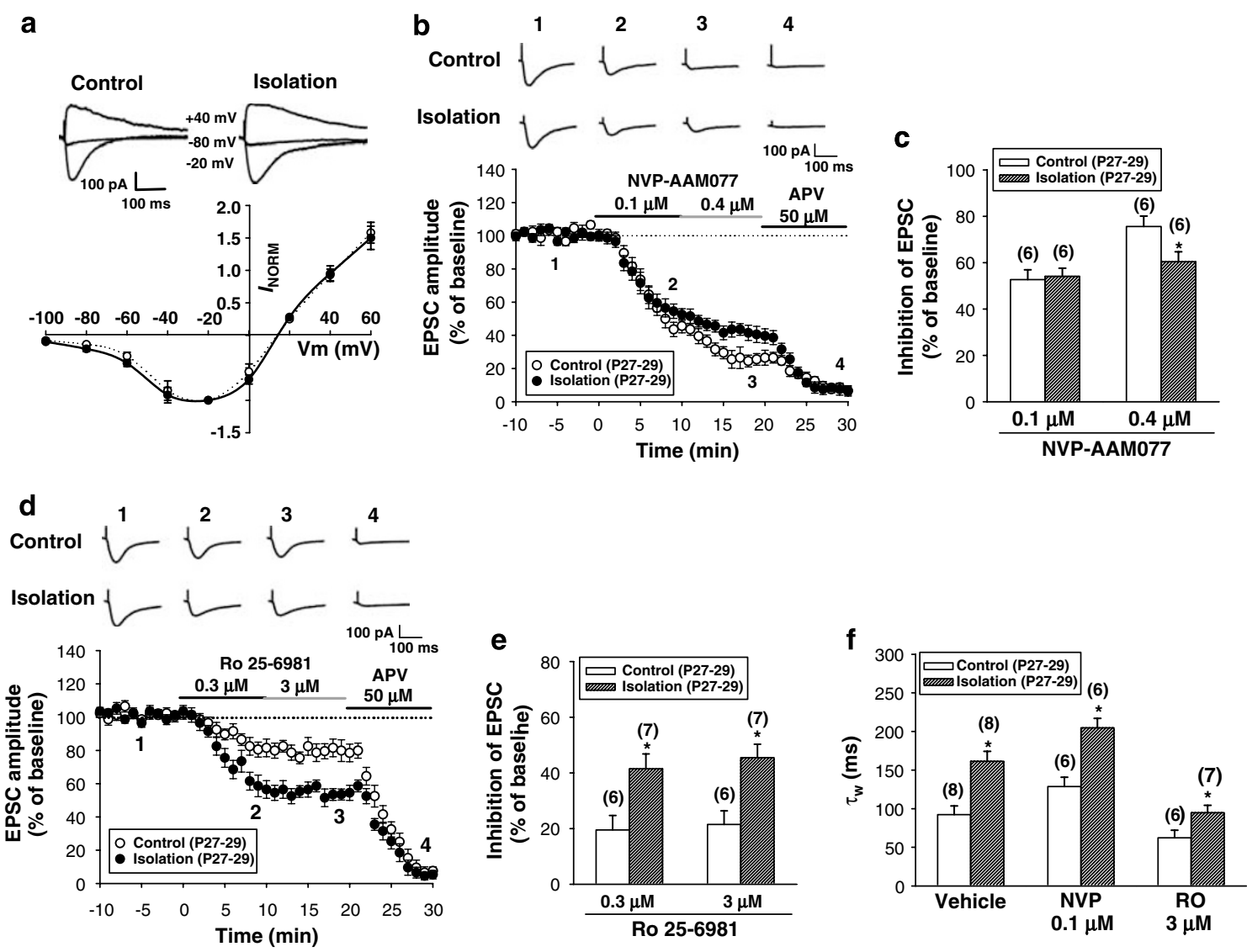

Figure 3 Increased NR2B subunit-containing NMRAR currents in hippocampal CAI neurons after neonatal isolation. (a) Current-voltage plots of the NMDA receptor-mediated EPSCs in neurons from neonatal isolated and control rats at P27-29. The currents exhibited strong outward retification. (b) Summary of experiments showing the time course of changes in NMDAR-mediated EPSC amplitude before and during the application of NVP-AAM077 $(0.1$ and $0.4 \mu \mathrm{M})$ and D-APV $(50 \mu \mathrm{M})$ in hippocampal CAI pyramidal neurons from both control and neonatal isolated rats at P27-29. (c) Averaged data showing percentage of maximal inhibition of NMDAR-mediated EPSCs by NVP-AAM077 (0.1 and $0.4 \mu M)$. (d) Summary of experiments showing the time course of changes in NMDAR-mediated EPSC amplitude before and during the application of Ro 25-698I (0.3 and $3 \mu \mathrm{M})$ and APV (50 $\mu \mathrm{M})$ in hippocampal CAI pyramidal neurons from both control and neonatal isolated rats at P27-29. (e) Averaged data showing percentage of maximal inhibition of NMDAR-

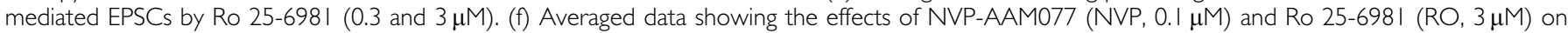
weighted time constant $\left(\boldsymbol{\tau}_{\mathbf{w}}\right)$ of decay of NMDAR-mediated EPSCs. The superimposed EPSCs in the upper panel illustrate respective recordings from example experiments taken at the time indicated by number. The numbers in parentheses indicate the number of slices examined (five to six rats for each group). ${ }^{*} p<0.05$ as compared with the control group.

slices from six rats), but not $0.1 \mu \mathrm{M}(54.1 \pm 3.5 \%, n=6$ slices from six rats), was significantly smaller in neurons from neonatal isolated rats when compared to that in neurons from control rats (Figure $3 \mathrm{~b}$ and $\mathrm{c}$ ). On the other hand, the reduction of the $\mathrm{EPSC}_{\mathrm{NMDA}}$ by Ro 25-6981 $(0.3 \mu \mathrm{M})$ was significantly greater in neurons from neonatal isolated rats $(39.6 \pm 4.8 \%$ of baseline, $n=7$ slices from six rats) compared with that of control rats $(19.6 \pm 3.6 \%$ of baseline, $n=6$ slices from five rats) (Figure $3 \mathrm{~d}$ and e). Application of a higher dose of Ro 25-6981 ( $3 \mu \mathrm{M})$ to the same neurons did not produce a further reduction, indicating that the dose of $0.3 \mu \mathrm{M}$ is sufficient to block the NR2B-containing EPSC $_{\mathrm{NMDA}}$ (Mutel et al, 1998) (Figure 3d). The remaining EPSC $_{\text {NMDA }}$ in the presence of Ro 25-6981 was completely and reversibly blocked by D-APV $(50 \mu \mathrm{M})$. As reported previously (Bartlett $e t a l, 2007$ ), we found that application of NVP-AAM077 increased the $\tau_{w}$ of decay of EPSC $\mathrm{NMDA}_{\mathrm{N}}$ whereas Ro 25-6981 decreased the $\tau_{w}$ of decay of $\mathrm{EPSC}_{\mathrm{NMDA}}$. Interestingly, we found that the decay of $\mathrm{EPSC}_{\mathrm{NMDA}}$ was still slower $(p<0.05)$ in neurons from neonatal isolated rats (95 $\pm 11 \mathrm{~ms}, n=7$ slices from six rats) than that in neurons from control rats ( $62 \pm 10 \mathrm{~ms}, n=6$ slices from five rats) in the presence of Ro 25-6981 (3 $\mu \mathrm{M})$ (Figure 3f). These results indicate that besides an increase in function of NR2Bcontaining NMDARs, an interfering glutamate uptake, subsequently resulting in enhanced spillover of synaptically released glutamate may also play a role, at least in part, in the slower decay kinetics of EPSC $_{\mathrm{NMDA}}$ observed in neurons from neonatal isolated rats.

Considering that LFS-LTD could be due to the preferential activation of synaptic or nonselective activation of both synaptic and extrasynaptic NMDARs, we tested whether the activation of extrasynaptic NMDARs is required for the induction of LFS-LTD observed in slices from neonatal isolated rats. To this end, LFS-LTD was examined when synaptic NMDARs were selectively blocked by pretreating slices with MK-801 $(5 \mu \mathrm{M})$, a specific blocker of the open NMDA channels, for 30 min (MacDonald and Nowak, 1990). To investigate whether the extrasynaptic NMDAR-dependent form of LTD could be induced under this condition, we initially examined the induction of LTD by LFS in the presence of the glutamate uptake inhibitor 
DL-TBOA, a protocol that has been shown to effectively induce a robust LTD by the activation of extrasynaptic NR2B-containing NMDARs in adult cortex and hippocampal CA1 region (Massey et al, 2004; Yang et al, 2005). After washout of MK-801 for $60 \mathrm{~min}$, LFS was delivered in the presence of DL-TBOA $(10 \mu \mathrm{M})$ in slices from control rats at P20-22, and the magnitude of LTD was examined. A reliable LTD was induced by LFS ( $n=5$ slices from three rats) (Supplementary Figure S1) and was blocked by D-APV $(50 \mu \mathrm{M})$ (data not shown). In contrast, LFS alone failed to induce LTD under this condition $(n=5$ slices from three rats), indicating that synaptic NMDARs involved in the induction of LTD are still blocked by MK-801 (Supplementary Figure S1). Consistently, we found that EPSC NMDA was still blocked at $60 \mathrm{~min}$ after washout of MK-801 ( $n=5$ slices from three rats) (Supplementary Figure S2a). Furthermore, no obvious difference in the effects of DL-TBOA $(10 \mu \mathrm{M})$ on EPSC $_{\text {NMDA }}$ was observed between MK-801 $(n=5$ slices from three rats) and vehicle ( $0.1 \% \mathrm{DMSO}, n=5$ slices from three rats) pretreatment slices from control rats at P20-22, providing further evidence that MK-801 blocked only synaptic NMDARs. Having confirmed that MK-801 pretreatment can specifically discriminate between synaptic and extrasynaptic NMDARs, we subsequently used this protocol to find out the localization of NMDARs involved in the induction of LFS-LTD in slices from neonatal isolation rats. As shown in Figure 4a, LTD can be induced by LFS in slices from control rats at P20-22 under vehicle-treated condition $(0.1 \%$ DMSO, $n=4$ slices from three rats). However, unlike in slices from control rats at P20-22, under this condition, LFS still induced LTD $(85.2 \pm 4.3 \%$ of baseline, $n=6$ slices from five rats; $p<0.05$ ), although this was smaller than that of LTD recorded in vehicle-treated condition ( $0.1 \%$ DMSO; $73.6 \pm 4.5 \%$ of baseline, $n=5$ slices from five rats) (Figure $4 \mathrm{~b}$ ). These results suggest that the activation of extrasynaptic NMDARs is involved, at least in part, in the induction of LFS-LTD in slices from neonatal isolated rats.

\section{Spillover and Temporal Summation of Glutamate Allow LFS-LTD}

Previous studies have shown that the induction of LTD by LFS in the presence of glutamate uptake inhibitors relies on the activation of extrasynaptic NR2B-containing NMDARs (Massey et al, 2004; Yang et al, 2005). We next investigated whether this mechanism could provide a possible explanation for why LFS can induce a robust LTD in slices from neonatal isolated rats. The best approach to address this question is to see if saturation of one form of LTD occludes induction of the other form at the same synapses. We initially compared the effect of blocking glutamate uptake on the inducibility of LTD by LFS in slices from neonatal isolated and control rats. We found that DL-TBOA $(10 \mu \mathrm{M}$, $n=5$ slices from four rats) significantly enhanced the LFSLTD $(p<0.05)$ in slices from control rats $(n=5$ slices from four rats) at P20-22 (Figure 4c). Although the slices from neonatal isolated rats at P27-29 also showed a higher level of LFS-LTD in the presence of DL-TBOA $(10 \mu \mathrm{M}, n=6$ slices from five rats) than that of LFS-LTD recorded in vehicle (aCSF)-treated slices ( $n=6$ slices from five rats), it did not reach statistical significance $(p=0.09)$ (Figure $4 d$ ).
We next examined whether the saturation of LFS-LTD can occlude the subsequent induction of LTD by LFS in the presence of DL-TBOA. We found that, in slices from control rats at P20-22, after LFS-LTD was fully established, LFS still resulted in the induction of LTD in the presence of DLTBOA $(10 \mu \mathrm{M}) \quad(n=5$ slices from four rats, $p<0.05)$ (Figure 4e). In contrast, in slices from neonatal isolated rats at P27-29, after LFS-LTD was fully established, no further LTD was induced by LFS in the presence of DLTBOA ( $n=6$ slices from six rats) (Figure $4 \mathrm{f}$ ). Such an occlusion experiment demonstrates that these two forms of LTD may share some common mechanisms in slices from neonatal isolated rats.

\section{Neonatal Isolation Modifies NMDAR Subunit Composition}

To determine whether neonatal isolation has specific effects on the expression of NMDAR subunit composition, we compared the levels of NR1, NR2A, and NR2B in the hippocampal CA1 region by western blot analysis on total homogenates. Immunoblot analysis of hippocampal CA1 homogenates reveals a substantial increase in NR2B levels in neonatal isolated rats at P14-42 (Figure $5 \mathrm{a}$ and $\mathrm{d}$ ). In the early period after neonatal isolation (P14-28), NR1 and NR2A levels in the homogenates were also significantly higher in slices from neonatal isolated rats relative to control rats (Figure 5a-d). However, NR1 and NR2A levels do not differ significantly between these two groups on P42.

The increase in the amount of NR2B could be resulted from increased gene expression. Quantitative real-time RTPCR analysis showed that the mRNA profiles for NR2B essentially resemble the protein expression. There was a significant increase in the level of NR2B mRNA at P14-42. Similarly, NR2B mRNA expression in hippocampal CA1 region was significantly greater in slices from neonatal isolated rats relative to control rats at P14-P28 (Figure 6c). We also detected significantly higher NR1 and NR2A mRNA levels in slices from neonatal isolated rats relative to control rats at P14-28, but not at P42 (Figure 6a and b).

On the basis of the data demonstrating the upregulation of NR1, NR2A, and NR2B levels after neonatal isolation, it was assumed that the elevated NMDAR subunit levels enhance LFS-LTD induction. To test this possibility, we ran a correlation between them in slices prepared from rats of different developmental ages (P12-42). The slices were first used for electrophysiological recordings, then subsequently microdissected and used for western blots allowing a direct comparison of LFS-LTD and NR2B levels in the same tissue. As shown in Figure 7b, there was a clear inverse correlation between the relative levels of NR2A protein and the magnitude of LFS-LTD $(r=0.63 ; p<0.001)$. In addition, the extent of LFS-LTD is strongly correlated with the relative levels of NR2B expression $(r=0.89 ; p<0.001)$ (Figure $7 \mathrm{c}$ ). We also demonstrated an inverse correlation between the NR2A/2B ratio and the extent of LFS-LTD $(r=0.82 ; p<0.001)$ (Figure $7 \mathrm{~d})$. However, there was no correlation between the relative levels of NR1 and the extent of LFS-LTD $(r=0.33 ; p=0.14)$ (Figure 7e). These results underscore the importance of developmental profile of NR2B levels in determining the induction of LFS-LTD in the hippocampal CA1 region. 

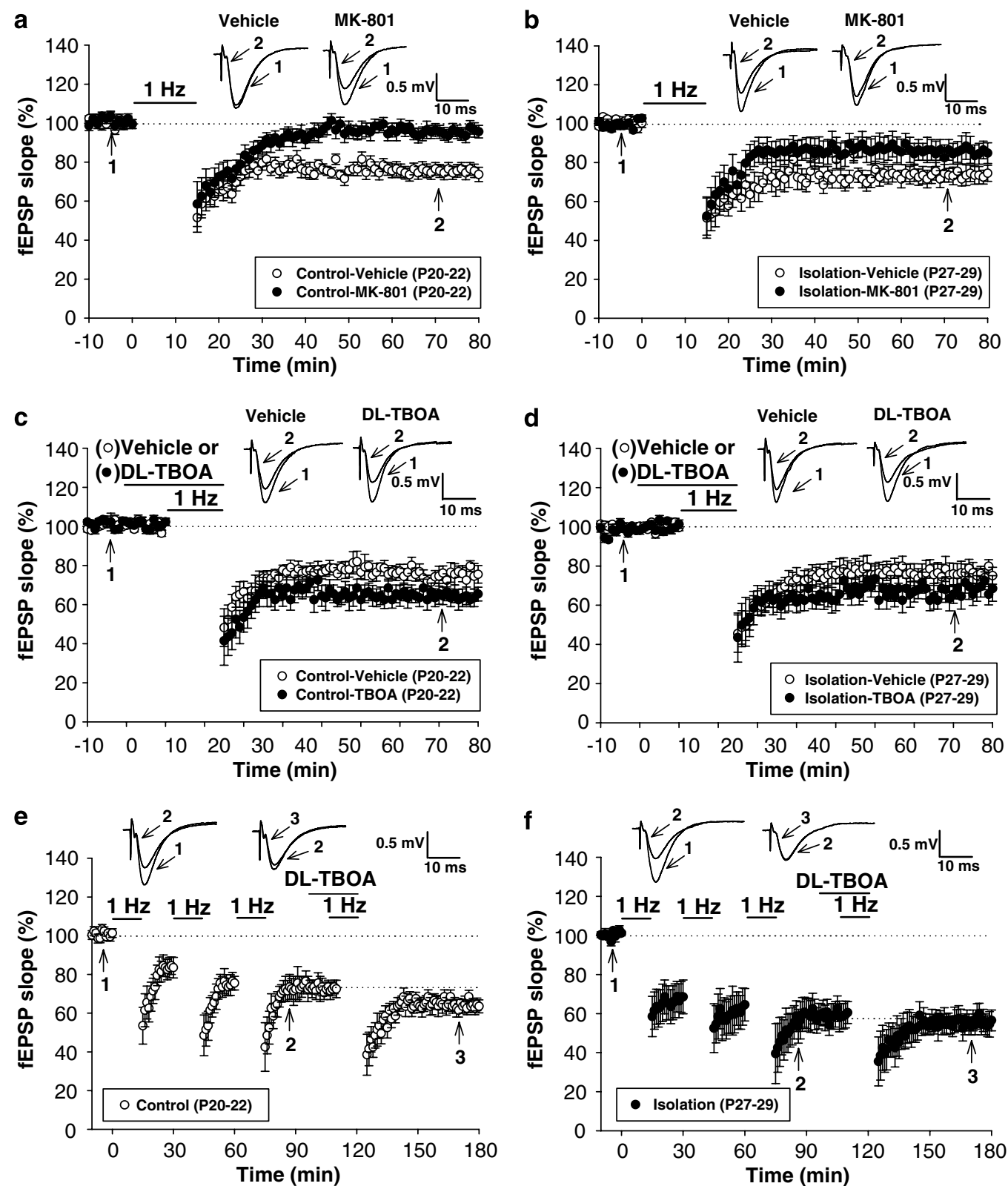

Figure 4 Induction of LFS-LTD in slices from neonatal isolated rats requires the activation of extrasynaptic NMDARs. (a) Summary of experiments showing the induction of LFS-LTD in slices from control rats at P20-22 was blocked when synaptic NMDARs were selectively blocked by pretreating slices with MK-80I $(5 \mu \mathrm{M})$ for $30 \mathrm{~min}$. (b) Summary of experiments showing that the induction of LFS-LTD in slices from neonatal isolated rats at P27-29 was partially inhibited when synaptic NMDARs were selectively blocked by pretreating slices with MK-80I (5 $\mu$ M) for 30 min. (c) Summary of experiments showing the induction of LFS-LTD in the presence of vehicle (aCSF) or DL-TBOA (I0 $\mu \mathrm{M}$ ) in slices from control rats at P20-22. (d) Summary of experiments showing the induction of LFS-LTD in the presence of vehicle (aCSF) or DL-TBOA (I0 $\mu \mathrm{M})$ in slices from neonatal isolated rats at P27-29. (e) Summary of experiments showing that, in slices from control rats at P20-22, after LFS-LTD was fully established (three episodes of I Hz for I 5 min stimuli), LFS in the presence of DL-TBOA $(10 \mu \mathrm{M})$ still caused a further LTD in synaptic transmission. (f) Summary of experiments showing that, in slices from neonatal isolated rats at P27-29, after LFS-induced LTD was fully established (three episodes of I Hz for I5 min stimuli), LFS in the presence of DL-TBOA $(10 \mu M)$ failed to induce additional synaptic depression. Dash lines show level of baseline. The superimposed fEPSPs in the inset illustrate respective recordings from example experiments taken at the time indicated by number.

\section{CRF Signaling System Mediates the Effects of Neonatal Isolation}

Giving the importance of the CRF system in both behavioral and hypothalamic-pituitary-adrenal responses to stress (Meaney, 2001), we examined its role in delaying the developmental decline of LFS-LTD induction by neonatal isolation. Inhibition of CRF-R1 with NBI27914 $(10 \mathrm{mg} / \mathrm{kg}$, intraperitoneal injection $1 \mathrm{~h}$ before isolation) but not CRFR2 with K41498 ( $2 \mathrm{nmol}$, i.c.v. injection $15 \mathrm{~min}$ before isolation) blocked the effect of neonatal isolation on the NR2B protein and mRNA expression (Figures 5 and 6 and Supplementary Figure S3) and the induction of LFS-LTD at P27-29 (Figure 8a and b). Likewise, i.c.v. injection of CRF $(1 \mu \mathrm{g} / \mu \mathrm{l}$ once per day) on $\mathrm{P} 3,-5$, and -7 mimicked the effect of neonatal isolation to increase the NR2B protein 

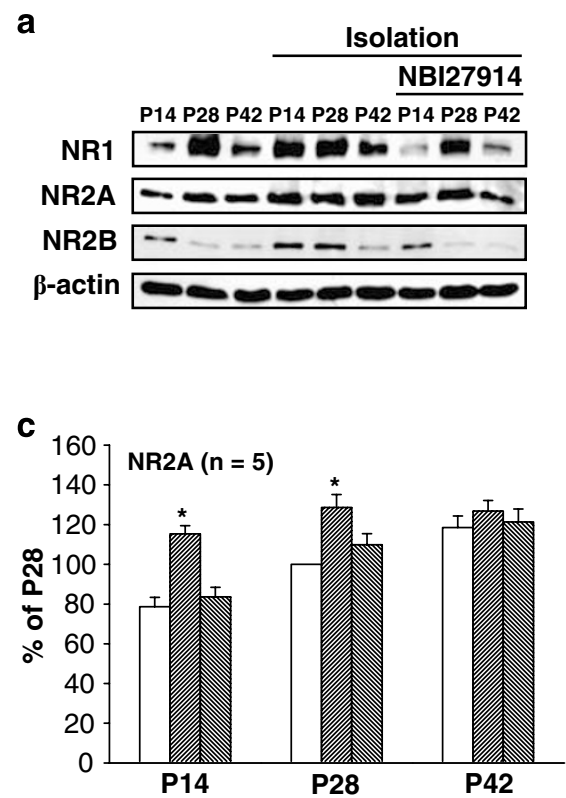
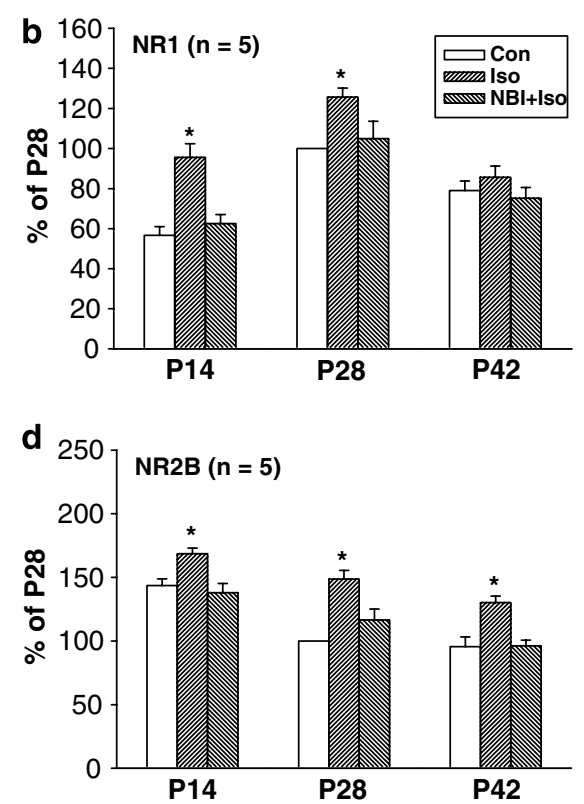

Figure 5 Neonatal isolation enhances developmental expression of NMDAR NRI, NR2A, and NR2B subunits. (a) A representative western blot showing that NBI279I4 prevents the upregulation of NRI, NR2A, and NR2B expression in the hippocampal CAI homogenates after neonatal isolation. (b-d) Corresponding densitometric analysis showing the relative postnatal developmental profile of hippocampal CAI NRI (b), NR2A (c), and NR2B (d) subunits in the control, neonatal isolation (Iso), and NBI279|4 (NBI) + neonatal isolation (Iso) groups. The numbers in parentheses indicate the number of animals examined. $*$ p $<0.05$ as compared with the control group.

expression (Supplementary Figure S4) and enhanced LTD induction at P27-29 (Figure 8c). Moreover, the effect of CRF was completely blocked by NBI27914 pretreatment. These findings suggest that the CRF signaling system elevates NR2B levels and may thus contribute to delay the developmental decline of LFS-LTD induction by neonatal isolation treatment.

\section{DISCUSSION}

In this study, we provide the first evidence that mild neonatal isolation from the day following birth until postnatal day 7 delays the developmental decline of LFS-LTD induction in the hippocampal CA1 region. We demonstrate that neonatal isolation elevates the expression of NR2B-containing NMDARs through the activation of CRF-R1, and the amount of NR2B-containing NMDARs correlates with age-dependency profile of LFS-LTD induction.

Accumulating evidence shows a direct effect of maternal care on hippocampal development and cognitive function in the offspring (Liu et al, 2000; Bredy et al, 2003). It has been shown that maternal care can increase hippocampal NMDAR levels, resulting in elevated BDNF expression and increased hippocampal synaptogenesis and neuronal survival, and thus enhanced spatial learning and memory in adulthood (Liu et al, 2000; Bredy et al, 2003). Conversely, prolonged maternal separation during the early postnatal period is associated with evidence for increased apoptosis, decreased neurotrophic factor expression, and reduced mossy fiber density in adulthood (Lee et al, 2001; Huot et al, 2002; Roceri et al, 2002). Our study extends these observations by showing that rats exposed to an appropriate bout of maternal separation are able to delay the developmental decline of LFS-LTD induction. This neonatal isolation-induced alteration of the effect of LFS occurs through a mechanism that is dependent on CRF, which is demonstrated by two lines of evidence. First, CRF mimics the effects of neonatal isolation on LFS-LTD. Second, the neonatal isolation-induced alteration of the LFS-LTD induction is specifically prevented by a CRF-R1 antagonist. Recently, it has been shown that in the early postnatal hippocampus, CRF is transiently expressed by Cajal-Retzius cells (Chen et al, 2001) and acts via the CRF-R1 to influence the dendritic differentiation in developing neurons (Chen et al, 2004). In mice deficient for CRF-R1, the dendritic trees of hippocampal pyramidal cells were exuberant, an effect that was also observed in normal hippocampi in vitro by the presence of CRF-R1 antagonist (Chen et al, 2004). A significant developmental decline in the expression levels of the CRF-R1 also occurs in the hippocampus, implying specific roles for the CRF during hippocampal development (Avishai-Eliner et al, 1996). These results support the concept that besides acting as a key stimulator of the stress response, endogenous CRF may be a critical contributor for the processes involved in maturation of hippocampal circuitry and function (Chen et al, 2004).

What mechanism might contribute to delay the developmental decline of LFS-LTD induction by neonatal isolation? One previous study has shown that the induction of LTD in the hippocampal CA1 region is specifically related to NR2Bcontaining NMDARs (Liu etal, 2004). However, we found that the NR2B-selective antagonists, Ro 25-6981 and ifenprodil, at concentrations that clearly reduce NMDARmediated synaptic currents, had no significant effect on LFS-LTD in slices from control rats. However, LTD was inhibited by NVP-AAM077, at a concentration that blocks 

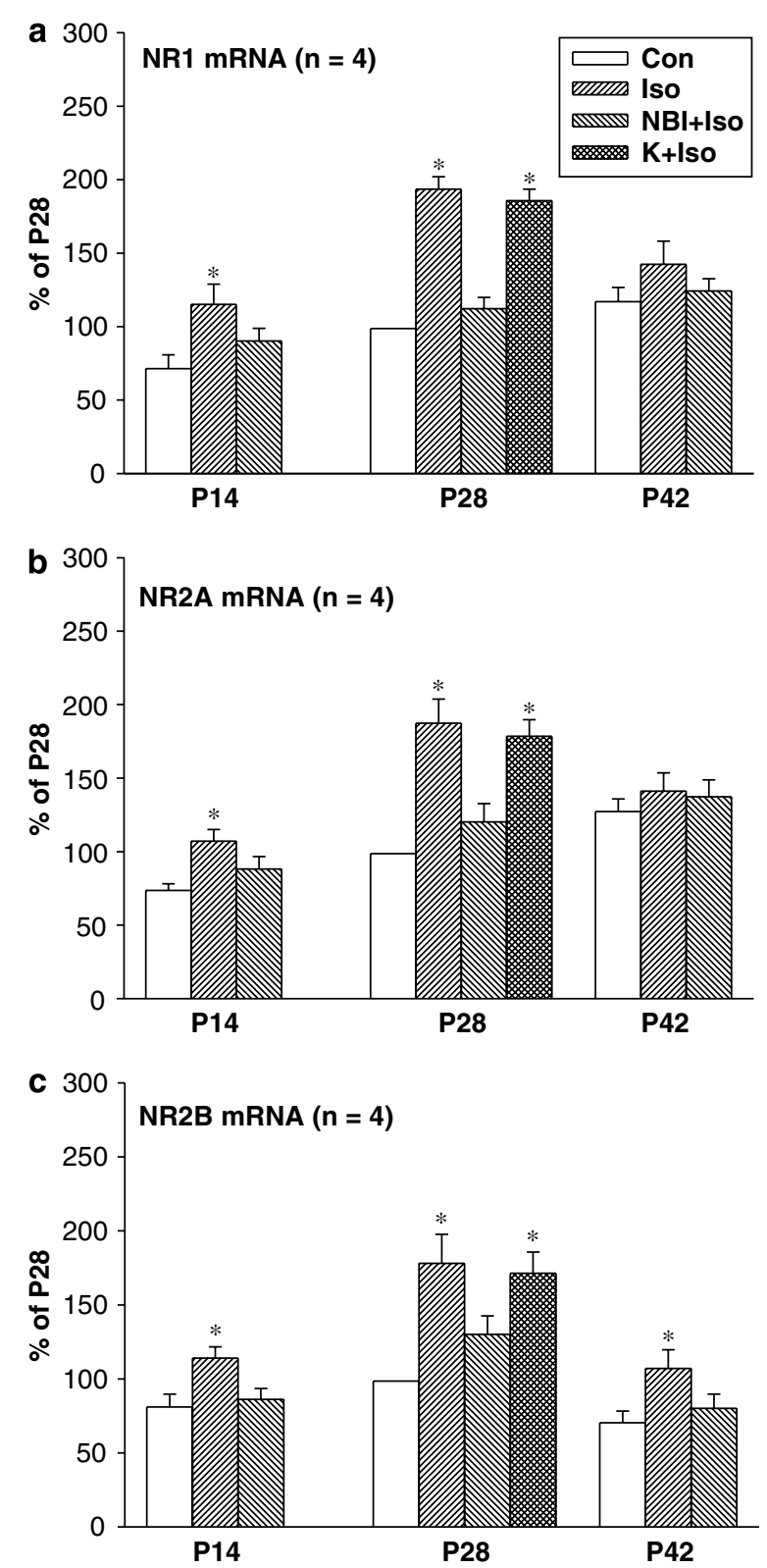

Figure 6 Neonatal isolation enhances the developmental expression of NMDAR NRI, NR2A, and NR2B mRNAs. (a-c) Real-time PCR analysis showing the relative postnatal developmental profile of hippocampal CAI NRI (a), NR2A (b), and NR2B (c) mRNA expression in the control, neonatal isolation (Iso), NBI279|4 (NBI) + neonatal isolation (Iso), and $\mathrm{K}$ $(\mathrm{K} 4 \mathrm{I498})+$ neonatal isolation (Iso) groups. The numbers in parentheses indicate the number of animals examined. $* p<0.05$ as compared with the control group.

both NR2A- and NR2B-containing NMDARs. Our results favor an alternative hypothesis suggesting that both NR2Aand NR2B-containing NMDARs contributed to LTD (Bartlett et al, 2007; Morishita et al, 2007). However, our findings are not consistent with a recent report showing that Ro $25-6981(0.5$ or $3 \mu \mathrm{M})$ and ifenprodil $(3 \mu \mathrm{M})$ can completely block the induction of LTD by LFS in the CA1 region of the hippocampus (Liu et al, 2004). The basis for the difference in our results and those of Liu et al (2004) is not clear. The same rat species (Sprague-Dawley) at approximately the same age were used in these experiments.
It is therefore possible that differences in a number of subtle experimental variables account for this apparent discrepancy. We were surprised to find that Ro 25-6981 and ifenprodil completely blocked the LFS-LTD in slices from neonatal isolated rats, although NVP-AAM077 also produced a significant inhibition of LTD at higher concentration. One simple explanation for these findings is that the enhancement of NR2B-containing NMDAR functions may contribute to the observed LFS-LTD in slices from neonatal isolated rats. This notion is supported by the observations that the level of NR2B subunits is significantly upregulated in the hippocampal CA1 region after neonatal isolation and the increased NR2B-containing NMDARs contributed to enhance NMDAR-mediated synaptic currents in the hippocampal CA1 neurons. Although our results established a positive correlation between the developmental patterns of NR2B subunits and LFS-LTD, we do not think that changes in total levels of NR2B expression may account for all the ability to trigger LFS-LTD in the neonatal isolated rats. Indeed, we also detected a significant increase in both NR1 and NR2A subunit expression after neonatal isolation. Although NVP-AAM077, at the NR2A-selective concentration of $0.1 \mu \mathrm{M}$, had no effect on the induction of LFS-LTD, we cannot exclude the changes in relative abundance of NR2A and NR2B subunits that also contribute to promote LTD induction (Bear, 2003; Chen and Bear, 2007). In fact, we also observe an inverse correlation between the NR2A/ NR2B ratio and the extent of LFS-LTD.

At most mature glutamatergic synapses, NR2B-containing NMDARs appeared predominantly at extrasynaptic sites (Stocca and Vicini, 1998; Tovar and Westbrook, 1999). Two lines of evidence suggest that neonatal isolation facilitates the induction of LFS-LTD through, at least in part, the activation of extrasynaptic NB2B-containing NMDARs. First, the magnitude of LFS-LTD in slices from neonatal isolated rats was only partially affected by pretreating slices with MK-801 to selectively block synaptic NMDARs. Second, saturation of LFS-LTD can occlude the subsequent induction of LTD by LFS in the presence of glutamate uptake inhibitor, suggesting some overlapping mechanisms. In fact, previous studies have demonstrated that blocking glutamate uptake may result in the induction of LTD by allowing glutamate released by LFS to activate extrasynaptic NMDARs (Chen and Diamond, 2002; Massey et al, 2004). A question arises as to how the glutamate released by LFS might activate extrasynaptic NMDARs to induce LTD in slices from neonatal isolated rats. It is generally thought that under normal conditions, the synaptically released glutamate is short lived and is unlikely to be sufficient to activate extrasynaptic receptors. The inclusion of extrasynaptic NMDARs in a synaptic event appears to vary according to several parameters, including the location and degree of saturation of neuronal and astroglial transporters, the activity of transporters, and the amount, timing, and proximity of glutamate release (van Zundert et al, 2004). Thus, an intriguing possibility is that neonatal isolation may cause a decrease in glutamate uptake, which results in the spillover and temporal summation of synaptically released glutamate by LFS to activate extrasynaptic NR2B-containing NMDARs. Consistent with this, we found that the decay of EPSC $_{\mathrm{NMDA}}$ was still slower in neurons from neonatal isolated rats than that in neurons from control rats after 

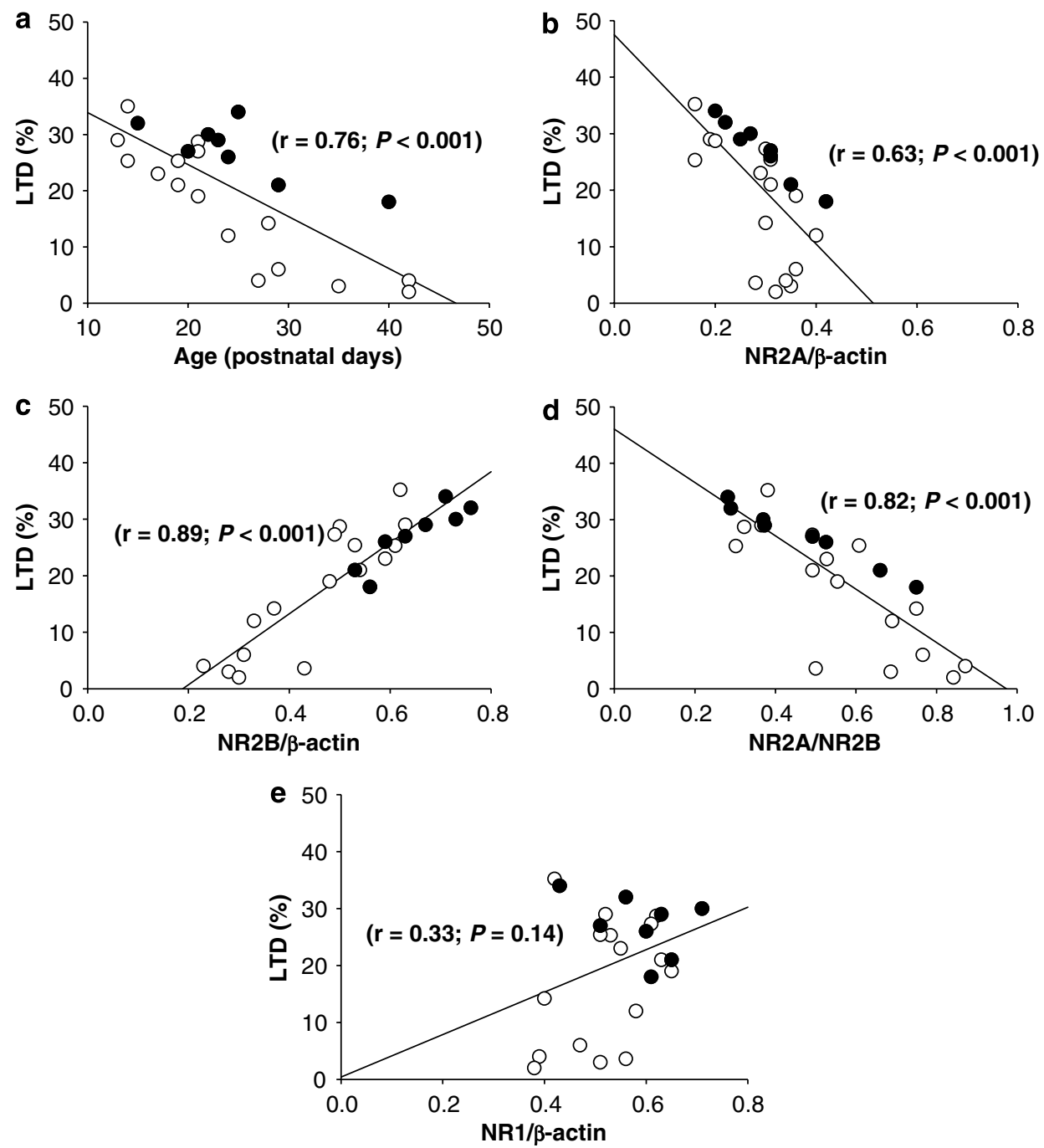

Figure 7 The expression of hippocampal CAI LFS-LTD. (a) A significant negative correlation is evident between the age and the extent of LFS-LTD expression in slices from control $(\mathrm{O})$ or neonatal isolated $(\mathbf{O})$ rats. (b) A significant negative correlation is evident between the relative amount of NR2A subunit and the extent of LFS-LTD expression. (c) A clear positive correlation is evident between the relative amount of NR2B subunit and the extent of LFS-LTD expression. (d) A significant negative correlation is evident between the relative ratio of NR2A/NR2B and the extent of LFS-LTD expression. (e) The extent of LFS-LTD is not correlated with the relative amount of NRI subunit. The extent of LTD was calculated at 50 min after LFS.

blockade of NR2B-containing NMDARs. However, additional studies will be necessary to examine this hypothesis.

Correlated increases in the levels of NR2B mRNA and protein in the CA1 region of the hippocampus following neonatal isolation strongly suggest that this regulation occurs primarily at the transcriptional level. The molecular mechanism underlying the neonatal isolation-induced elevation of NR2B gene transcription is unknown; however, two possible mechanisms can be proposed. Because the promoter region of NR2B gene contains a cAMP responsive element-binding protein (CREB) consensus sequence (Myers et al, 1999) and the activation of CRF-R1 is known to stimulate $G_{s}$ protein that activates adenylyl cyclase, leading to cAMP accumulation with subsequent protein kinase A (PKA) activation and CREB phosphorylation (De Souza, 1995), it is therefore likely that neonatal isolation may promote the developmental production of NR2B levels through the enhanced CRF production and release, and the consequent activation of CRF-R1 in the hippocampal CA1 neurons to increase PKA-dependent signaling. An alternative possibility is that neonatal isolation may slow the developmental decline of the NR2B mRNA levels (Naassila and Daoust, 2002).

What could be the functional significance of the developmental change in the induction rules for LTD? Emerging evidence supports the notion that the developmental decline of LFS-LTD in the CA1 region of the hippocampus is not due to a loss of ability of synaptic transmission to depress but rather due to changes in the induction protocols or synaptic machinery responsible for LTD induction (Kemp et al, 2000; Kemp and Bashir, 2001). It has been suggested that this developmental plasticity change may result from the age-related alterations in the NMDAR subunit composition and/or location (Dumas, 2005). As LTD may be causally related to activity-dependent weakening and elimination of synaptic connections in the developing nervous system (Zhou et al, 2004), this change may provide the basis for synaptic connections from greater 


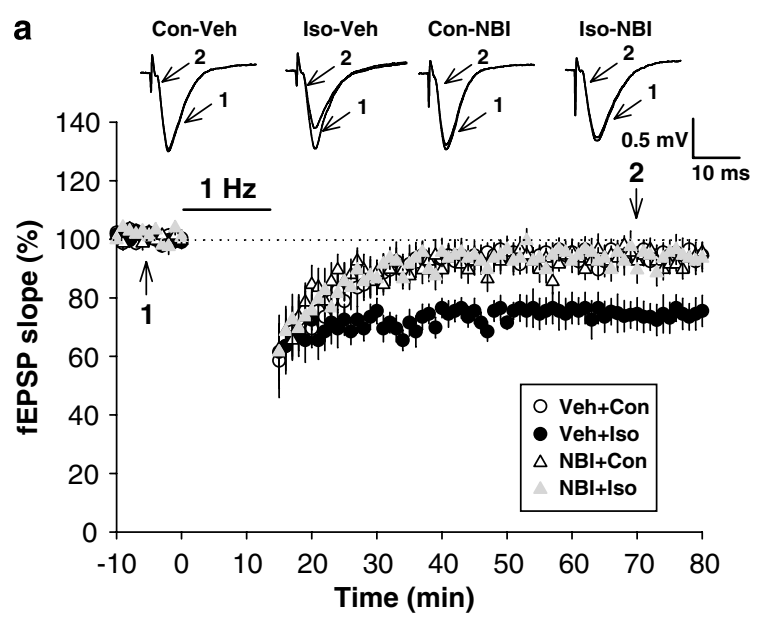

sensitive to greater stable condition optimal for information processing and memory storage. Thus, a delaying maturation change in the induction rules of LTD may affect the activity-dependent refinement of synaptic connectivity.

In conclusion, our results show that neonatal isolation is able to delay the developmental decline of LFS-LTD induction in the hippocampal $\mathrm{CA} 1$ region and more importantly, identify specific molecular mechanisms to support this contention. These findings also underscore the importance of the early maternal care in regulating of the maturation of synaptic functions.

\section{ACKNOWLEDGEMENTS}

This work was supported by a research grant (NSC96-2752B-006-002-PAE) from the National Science Council of Taiwan.

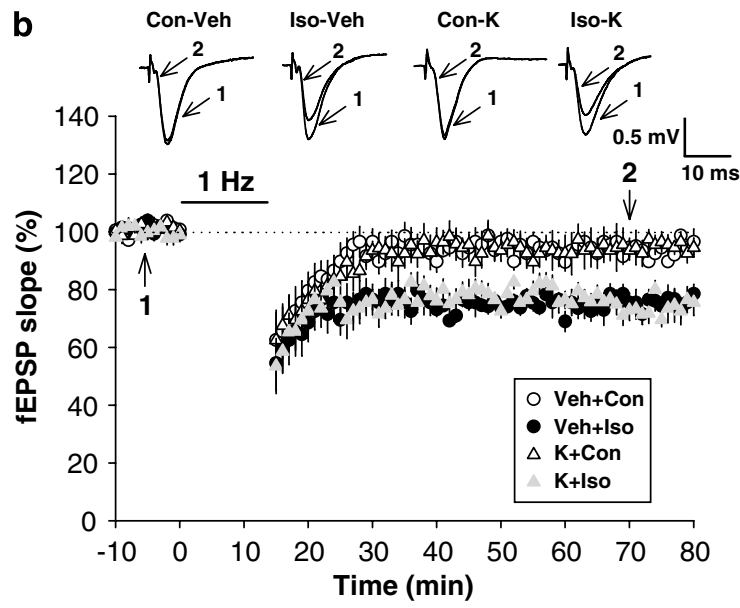

\section{CONFLICT OF INTEREST}

We declare that there are no actual or potential conflicts of interest. We affirm that there are no financial, personal, or other relationships with other people or organizations that have inappropriately influenced or biased our work.

\section{REFERENCES}

Auberson YP, Allgeier H, Bischoff S, Lingenhoehl K, Moretti R, Schmutz M (2002). 5-Phosphonomethylquinoxalinediones as competitive NMDA receptor antagonists with a preference for the human $1 \mathrm{~A} / 2 \mathrm{~A}$, rather than $1 \mathrm{~A} / 2 \mathrm{~B}$ receptor composition. Bioorg Med Chem Lett 12: 1099-1102.

Avishai-Eliner S, Yi SJ, Baram TZ (1996). Developmental profile of messenger RNA for the corticotropin-releasing hormone receptor in the rat limbic system. Dev Brain Res 91: 159-163.

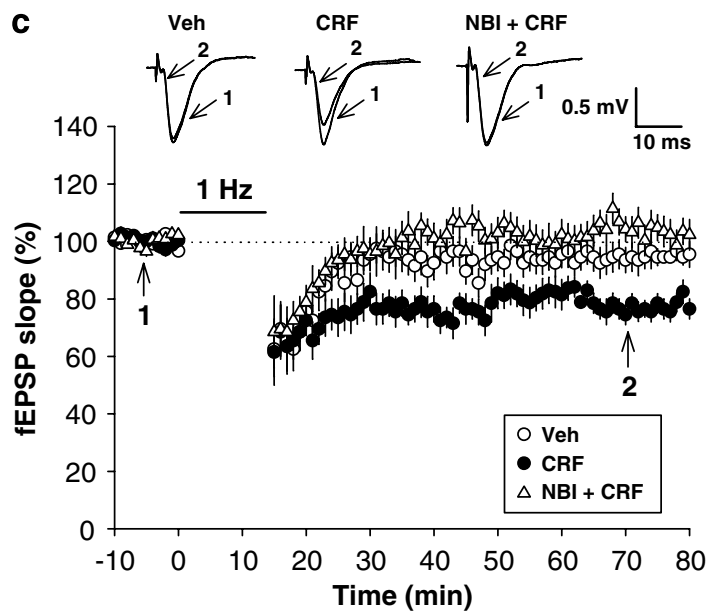

Figure 8 The activation of CRF-RI mediates the effect of neonatal isolation. (a) Summary of experiments showing that the inhibition of CRF$\mathrm{RI}$ with NBI279/4 (I0 mg/kg, intraperitoneal injection I h before isolation) prevented the facilitatory effects of neonatal isolation on LFS-LTD at P2729. (b) Summary of experiments showing that inhibition of CRF-R2 with K4I 498 (I nM of I $\mu$ l, i.c.v. injection I h before isolation) did not significantly affect the effects of neonatal isolation on LFS-LTD. (c) CRF injections ( $\mathrm{ng} / \mu \mathrm{l}$, i.c.v. injection every second day from P3 to P7) mimicked the effect of neonatal isolation to facilitate the induction of LFS-LTD. Dash lines show level of baseline. The superimposed fEPSPs in the inset illustrate respective recordings from example experiments taken at the time indicated by number. $(n=6-8$ slices from five to six rats for each group).

Bartlett TE, Bannister NJ, Collett VJ, Dargan SL, Massey PV, Bortolotto ZA et al (2007). Differential roles of NR2A and NR2Bcontaining NMDA receptors in LTP and LTD in the CA1 region of two-week old rat hippocampus. Neuropharmacology 52: $60-70$.

Bear MF (2003). Bidirectional synaptic plasticity: from theory to reality. Philos Trans R Soc Lond B Biol Sci 358: 649-655.

Bliss TV, Collingridge GL (1993). A synaptic model of memory: long-term potentiation in the hippocampus. Nature 361: 31-39.

Bliss TV, Lomo T (1973). Long-lasting potentiation of synaptic transmission in the dentate area of the anaesthetized rabbit following stimulation of the perforant path. J Physiol 232: 331-356.

Bredy TW, Grant RJ, Champagne DL, Meaney MJ (2003). Maternal care influences neuronal survival in the hippocampus of the rat. Eur J Neurosci 18: 2903-2909.

Burgess N, Maguire EA, O'Keefe J (2002). The human hippocampus and spatial and episodic memory. Neuron 35: 625-641.

Chen S, Diamond JS (2002). Synaptically released glutamate activates extrasynaptic NMDA receptors on cells in the ganglion cell layer of rat retina. J Neurosci 22: 2165-2173.

Chen WS, Bear MF (2007). Activity-dependent regulation of NR2B translation contributes to metaplasticity in mouse visual cortex. Neuropharmacology 52: 200-214.

Chen Y, Bender RA, Brunson KL, Pomper JK, Grigoriadis DE, Wurst W et al (2004). Modulation of dendritic differentiation by corticotropin-releasing factor in the developing hippocampus. Proc Natl Acad Sci USA 101: 15782-15787.

Chen Y, Bender RA, Frotscher M, Baram TZ (2001). Novel and transient populations of corticotropin-releasing hormone-expressing 
neurons in developing hippocampus suggest unique functional roles: a quantitative spatiotemporal analysis. J Neurosci 21: 7171-7181.

De Souza EB (1995). Corticotropin-releasing factor receptors: physiology, pharmacology, biochemistry and role in central nervous system and immune disorders. Psychoneuroendocrinology 20: 789-819.

Dudek SM, Bear MF (1992). Homosynaptic long-term depression in area CA1 of hippocampus and effects of $N$-methyl-D-aspartate receptor blockade. Proc Natl Acad Sci USA 89: 4363-4367.

Dumas TC (2005). Developmental regulation of cognitive abilities: modified composition of a molecular switch turns on associative learning. Prog Neurobiol 76: 189-211.

Fischer G, Mutel V, Trube G, Malherbe P, Kew JN, Mohacsi E et al (1997). Ro 25-6981, a highly potent and selective blocker of $\mathrm{N}$-methyl-D-aspartate receptors containing the NR2B subunit. Characterization in vitro. J Pharmacol Exp Ther 283: 1285-1292.

Han BH, Holtzman DM (2000). BDNF protects the neonatal brain from hypoxic-ischemic injury in vivo via the ERK pathway. J Neurosci 20: 5775-5781.

Huang CC, Chou PH, Yang CH, Hsu KS (2005). Neonatal isolation accelerates the developmental switch in the signalling cascades for long-term potentiation induction. J Physiol 569: 789-799.

Huot RL, Plotsky PM, Lenox RH, McNamara RK (2002). Neonatal maternal separation reduces hippocampal mossy fiber density in adult Long Evans rats. Brain Res 950: 52-63.

Katz LC, Shatz CJ (1996). Synaptic activity and the construction of cortical circuits. Science 274: 1133-1138.

Kemp N, Bashir ZI (1997). NMDA receptor-dependent and -independent long-term depression in the CA1 region of the adult rat hippocampus in vitro. Neuropharmacology 36: 397-399.

Kemp N, Bashir ZI (2001). Long-term depression: a cascade of induction and expression mechanisms. Prog Neurobiol 65: 339-365.

Kemp N, McQueen J, Faulkes S, Bashir ZI (2000). Different forms of LTD in the CA1 region of the hippocampus: role of age and stimulus protocol. Eur J Neurosci 12: 360-366.

Lawrence AJ, Krstew EV, Dautzenberg FM, Ruhmann A (2002). A The highly selective CRF2 receptor antagonist K41498 binds to presynaptic $\mathrm{CRF}_{2}$ receptors in rat brain. $\mathrm{Br} \mathrm{J}$ Pharmacol 136: 896-904.

Lee HJ, Kim JW, Yim SV, Kim MJ, Kim SA, Kim YJ et al (2001). Fluoxetine enhances cell proliferation and prevents apoptosis in dentate gyrus of maternally separated rats. Mol Psychiatry 6: 725-728.

Liu D, Diorio J, Day JC, Francis DD, Meaney MJ (2000). Maternal care, hippocampal synaptogenesis and cognitive development in rats. Nat Neurosci 3: 799-806.

Liu L, Wong TP, Pozza MF, Lingenhoehl K, Wang Y, Sheng M et al (2004). Role of NMDA receptor subtypes in governing the direction of hippocampal synaptic plasticity. Science 304: 1021-1024.

MacDonald JF, Nowak LM (1990). Mechanisms of blockade of excitatory amino acid receptor channels. Trends Pharmacol Sci 11: 167-172.

Malenka RC, Bear MF (2004). LTP and LTD: an embarrassment of riches. Neuron 44: 5-21.

Martin SJ, Grimwood PD, Morris RG (2000). Synaptic plasticity and memory: an evaluation of the hypothesis. Annu Rev Neurosci 23: 649-711.

Massey PV, Johnson BE, Moult PR, Auberson YP, Brown MW, Molnar E et al (2004). Differential roles of NR2A and NR2Bcontaining NMDA receptors in cortical long-term potentiation and long-term depression. J Neurosci 24: 7821-7828.

Meaney MJ (2001). Maternal care, gene expression, and the transmission of individual differences in stress reactivity across generations. Annu Rev Neurosci 24: 1161-1192.
Monyer H, Burnashev N, Laurie DJ, Sakmann B, Seeburg PH (1994). Developmental and regional expression in the rat brain and functional properties of four NMDA receptors. Neuron 12: 529-540.

Morishita W, Lu W, Smith GB, Nicoll RA, Bear MF, Malenka RC (2007). Activation of NR2B-containing NMDA receptors is not required for NMDA receptor-dependent long-term depression. Neuropharmacology 52: 71-76.

Mulkey RM, Malenka RC (1992). Mechanisms underlying induction of homosynaptic long-term depression in area CA1 of the hippocampus. Neuron 9: 967-975.

Mutel V, Buchy D, Klingelschmidt A, Messer J, Bleuel Z, Kemp JA et al (1998). In vitro binding properties in rat brain of $[3 \mathrm{H}] \mathrm{Ro}$ 25-6981, a potent and selective antagonist of NMDA receptors containing NR2B subunits. J Neurochem 70: 2147-2155.

Myers SJ, Dingledine R, Borges K (1999). Genetic regulation of glutamate receptor ion channels. Annu Rev Pharmacol Toxicol 39: 221-241.

Naassila M, Daoust M (2002). Effect of prenatal and postnatal ethanol exposure on the developmental profile of mRNAs encoding NMDA receptor subunits in rat hippocampus. J Neurochem 80: 850-860.

Paupard MC, Friedman LK, Zukin RS (1997). Status epilepticusinduced alterations in metabotropic glutamate receptor expression in young and adult rats. J Neurosci 17: 8588-8595.

Pickering C, Gustafsson L, Cebere A, Nylander I, Liljequist S (2006). Repeated maternal separation of male Wistar rats alters glutamate receptor expression in the hippocampus but not the prefrontal cortex. Brain Res 1099: 101-108.

Roceri M, Hendriks W, Racagni G, Ellenbroek BA, Riva MA (2002). Early maternal deprivation reduces the expression of BDNF and NMDA receptor subunits in rat hippocampus. Mol Psychiatry 7: 609-616.

Rumbaugh G, Vicini S (1999). Distinct synaptic and extrasynaptic NMDA receptors in developing cerebellar granule neurons. J Neurosci 19: 10603-10610.

Sala C, Rudolph-Correia S, Sheng M (2000). Developmentally regulated NMDA receptor-dependent dephosphorylation of cAMP response element-binding protein (CREB) in hippocampal neurons. J Neurosci 20: 3529-3536.

Seeburg PH (1993). The TINS/TiPS Lecture. The molecular biology of mammalian glutamate receptor channels. Trends Neurosci 16: $359-365$.

Squire LR (1992). Memory and the hippocampus: a synthesis from findings with rats, monkeys, and humans. Psychol Rev 99: 195-231.

Stocca G, Vicini S (1998). Increased contribution of NR2A subunit to synaptic NMDA receptors in developing rat cortical neurons. J Physiol 507: 13-24.

Tovar KR, Westbrook GL (1999). The incorporation of NMDA receptors with a distinct subunit composition at nascent hippocampal synapses in vitro. J Neurosci 19: 4180-4188.

van Zundert B, Yoshii A, Constantine-Paton M (2004). Receptor compartmentalization and trafficking at glutamate synapses: a developmental proposal. Trends Neurosci 27: 428-437.

Williams K (1993). Ifenprodil discriminates subtypes of the $\mathrm{N}$-methyl-D-aspartate receptor: selectivity and mechanisms at recombinant heteromeric receptors. Mol Pharmacol 44: 851-859.

Yang CH, Huang CC, Hsu KS (2005). Behavioral stress enhances hippocampal CA1 long-term depression through the blockade of the glutamate uptake. J Neurosci 25: 4288-4293.

Zhang LI, Poo MM (2001). Electrical activity and development of neural circuits. Nat Neurosci 4: 1207-1214.

Zhou Q, Homma KJ, Poo MM (2004). Shrinkage of dendritic spines associated with long-term depression of hippocampal synapses. Neuron 44: 749-757.

Supplementary Information accompanies the paper on the Neuropsychopharmacology website (http://www.nature.com/npp) 